\title{
Performance evaluation of microfinance institutions and local wisdom-based management con- cept
}

\section{Gusti Ayu Purnamawatia ${ }^{{ }^{*}}$ and Ni Ketut Sari Adnyani ${ }^{b}$}

${ }^{a}$ Economic Faculty, Universitas Pendidikan Ganesha, Indonesia ${ }^{b}$ Law and Social Science Faculty, Universitas Pendidikan Ganesha, Indonesia

\section{CH RON I CLE ABSTRACT}

Article history:

Received: June 142019

Received in revised format: July

252019

Accepted: August 5, 2019

Available online:

August 5, 2019

Keywords:

Performance prism

Microfinance

Management

Local wisdom

\begin{abstract}
This study aims to evaluate the performance of microfinance institutions and local wisdom-based management concept. Quantitative approach is used in this study. The data analysis technique used in this study are quantitative and qualitative data analyses, which include the stakeholders and key performance indicators (KPI). Analytical Hierarchy Process (AHP) technique is used to determine the quality, Objective Matrix is used for scoring, and Traffic Light System is used for grouping in colors. The results of the study show that not only strategies, processes, and capabilities influence on the Lembaga Perkreditan Desa (LPD) (village credit institution) of Depeha Village, but also the stakeholder's satisfaction and contributions also influence the LPD. The strategy formulation is carried out by the LPD based on the stakeholders' determinants of satisfaction and Catur Purusa Artha concept (a traditional philosophy for life by Balinese Hinduism which means four goals in human life).
\end{abstract}

\section{Introduction}

Microfinance has gained universal recognition in various developing countries as an important tool to reduce poverty (Mustafa \& Saat, 2013; Kumar \& Gupta, 2011). The microfinance industry currently forms an integral part of the formal financial sector in various countries in the world (Rotich et al., 2015). The microfinance institution (Lembaga Perkreditan Desa/ LPD) is a savings and loan business entity that is closely related to the typical village structure in Bali. LPD as a microfinance institution is a unique business entity because it only exists in Bali and is managed based on the philosophy of the custom and Balinese culture which is strongly influenced by the majority religion in Bali, which is Hinduism. It is very difficult to distinguish the custom and religion from Balinese people, because each customary activity is carried out based on religious teachings and every religious activity involves the custom. The positive impact of LPD development is the increase and development of the economy of the people in rural areas. The cause of the LPD's success also comes from a pattern of community-based management based on family values (menyaman braya/kinship) and mutual cooperation in the framework of Balinese customs and culture. The people lived in village are the owners and managers of the LPD who carry out

* Corresponding author.

E-mail address: ayupurnama07@yahoo.com (I. G. A. Purnamawati) 
their duties and functions in the bond of commitment to prosperity and mutual progress. In an effort to meet short-term targets, a business entity, including LPDs, tends to use short-term strategies so that the value of the company tends to be ignored. Strategy is not a one-time activity, and thus organizations need to make continuous, yet systematic and logical changes in their strategy in order to better compete and survive (Ukil \& Akkas, 2017). Therefore, an integrated performance measurement is needed that is capable of measuring the performance of the Depeha village's LPD as a whole, both financial and nonfinancial aspects.

There are three popular performance measurement models that are considered to be chosen, namely the Balanced Scorecard, Integrated Performance Measurement System (IPMS), and Performance Prism. The Performance Prism model was developed by Kennerley and Neely (2002). A study by Taticchi et al. (2010) highlighted the performance measurement research and provided work updates. Neely (2005) analyzed the evolution of performance measurement research. Some problems are categorized as "the effectiveness of the performance assessment model", which is a challenge that must be solved in the future in the context of SMEs, namely by adjusting the development of performance measurement models based on the characteristics and needs of SMEs. The findings of this study regarding SME practices related to PMS may be the same in terms of fast-growing developing countries such as China, Malaysia, Hong Kong, Singapore, Indonesia, etc. But it might have different practices in the developed countries like England, US, Japan, Germany, etc. (Sharma et al., 2005). The management of Depeha village's LPD is based on the teachings of Catur Purusa Artha. Catur Purusa Artha is four goals in human life, which consists of Dharma, Artha, Kama, and Moksa. These four goals in human life were used as the four objectives of the LPD in Depeha village. The purpose of Dharma is the management of LPD based on honesty and truth to make a profit. In managing the LPD, appropriate strategies and adequate capabilities are needed, so that the process can run smoothly to generate profits. The purpose of the Artha is that the LPD profit funds are managed for the primary welfare of the village. Meanwhile, the purpose of Kama is that if the villagers are already prosperous, they can meet secondary and tertiary needs. In addition, the last is the purpose of Moksa as intended in the LPD is that if the welfare has been achieved then the villagers will be happy in terms of sekala (seen) and niskala (unseen). These last three objectives are closely related to stakeholders' satisfaction that is to be achieved by Depeha village's LPD. Besides being related to stakeholders' satisfaction, the three objectives are also related to stakeholder contributions. It is because in achieving prosperity, it is certain that contributions from villagers are needed so that the LPD can continue to grow. The four objectives also show that there is involvement between financial and non-financial aspects. This means the appropriate performance measurement to be carried out in the LPD of Depeha village is an integrated performance measurement, in this case is the Performance Prism model. Although the selection of this method was based on the superiority of each method and purpose of the LPD in Depeha village, but in reality, there was a problem in this LPD. The problem is regarding the level of bad debt found in the LPD of Depeha village. The number of bad debts in this LPD increased

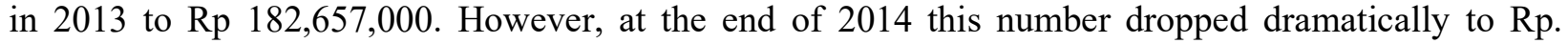
$73,648,000$. Despite a significant decline, this number is still categorized as high compared with the year before 2013. A significant reduction in the amount of bad debt in 2014 indicates that the LPD of Depeha village uses a stakeholder-oriented strategy so that stakeholders feel satisfied and make good contributions for the LPD. Through performance measurement based on the Performance Prism method, in addition to the financial aspects, the overall performance of the Depeha village's LPD will be known along with performance indicators that need to be improved to be able to increase the company value of the Depeha village's LPD. The improvements to each of the performance indicators are also expected to have a positive effect on the amount of bad debt at this LPD.

The research done by Youngbantao and Rompho (2015) evaluated the use of performance measures in performance prisms. The results showed that there were no significant differences in the use of these measures between companies in different cultures. A study by Najmi et al. (2012) presented a conceptual model for analyzing performance measurement systems (PMS) designed based on Performance Prism. The implications are focused on various factors such as organizational culture, management change, and 
action characteristics (level of action, managers who receive reports and supporting infrastructure). The research by Mersland and Strøm (2009) analyzed the relationship between corporate performance and governance of microfinance institutions. According to Subhan and Ghani (2011), Adianto et al. (2014) regarding the performance measurement is using weighting methods with Analytical Hierarchy Process (AHP) to determine the priority value scale of each KPI, Scoring System with Objectives Matrix (OMAX) method and Traffic Light System to determine the level of each KPI for companies at the corporate level. Performance Prism is a model that describes organizational performance as a prism, namely a three-dimensional construct with five sides consisting of stakeholders' satisfaction, strategy, process, capability and stakeholders' contributions (Neely et al., 2002). Key Performance Indicators are financial and non-financial indicators used by the organization to estimate and fortify how successful the organization is, which previously aimed to set targets that are able to survive for a long time (Velimirović et al., 2011). Key Performance Indicators (KPIs) help an organization in setting and measuring progress towards organizational goals (Sawang, 2011). AHP is a multicriteria decision making technique, where quantitative factors and qualitative factors are combined (Saaty, 2008). An alternative assessment used by Bourgeois (2005) which uses a scale of 0.1 to 1.9 is considered more logical. If A is far more important / preferred to $\mathrm{B}$, then the score of $\mathrm{A}$ is 1.6 and the core of $\mathrm{B}$ is 0.4 . This method of assessment will be used in this study. Objective Matrix (OMAX) is a scoring method of the performance of a company where the assessment is carried out on qualitative criteria related to the performance of the company (Riggs, 1987). The function of Traffic Light System is considered as a sign to determine whether the score of a performance indicator requires an improvement or not (Cahyawati et al., 2013).

\section{Research methodology}

The thinking framework is outlined in Fig. 1.

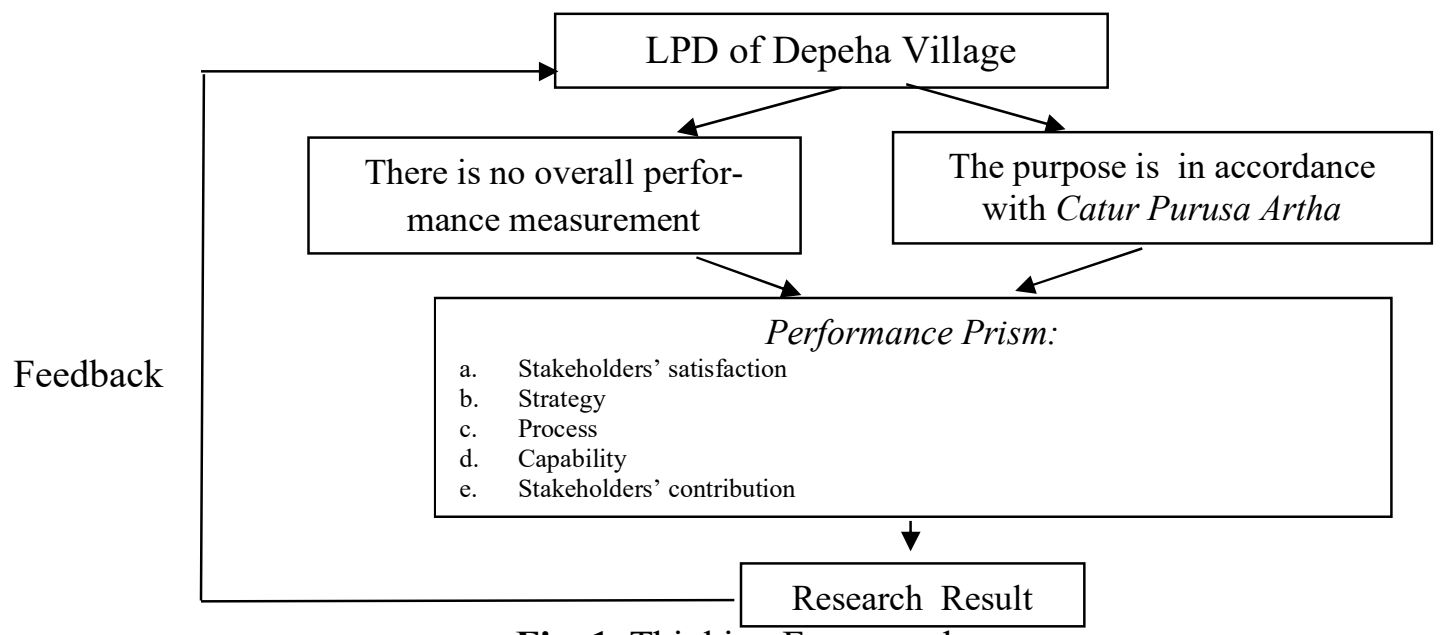

Fig. 1. Thinking Framework

The study was conducted at the LPD of Depeha Village which is located in Kubutambahan District, Buleleng Regency, Bali. This location was chosen because the LPD had never carried out a comprehensive measurement of organizational performance and there was a match between the objectives of the LPD and the method of Performance Prism. Another reason for choosing this location was that the number of non-performing loans in the LPD increased sharply in 2012 and 2013 but this number was able to be reduced and it decreased more than 50 percent compared with the previous year in 2014 . The subject of this study was the LPD of Depeha Village, including all stakeholders of LPD in Depeha village. The samples in the study were all LPD employees and several stakeholders. Determination of the sample in this study was adjusted to the characteristics of different stakeholders. In customer stakeholders, the sampling technique used is the Simple Random Sampling technique because it does not pay attention to equality in the LPD of Depeha village. In government stakeholders and the surrounding community, the sampling technique used is Purposive Sampling technique. The criteria set out in the Purposive Sampling 
technique include the village's teacher and is aware of the development of the LPD in Depeha village. The data needed in this study will be collected by various data collection techniques, such as: In-depth Interviewing Techniques, Observation Techniques, Survey Techniques, and Document Studies. The interview guide used is a semi-structured interview guide because it only contains questions in general but is directed. The types of questions that will be asked in this study are adjusted to the characteristics of the interviewees. In this study there were two types of questionnaires used. Questionnaire I was given to the Head of the LPD of Depeha village and the secretary, which contains weighting for each KPI identified. Questionnaire II was given to all employees of LPD in Depeha village except cleaning service. Questionnaire II contains the level of achievement of each KPI according to employees and is presented in a range of score 1-5.

\subsection{Data analysis}

\subsection{Analytical Hierarchy Process (AHP)}

The steps in the Analytical Hierarchy Process begin with defining the problem and determining the desired solution, then proceed by making a hierarchical structure that starts with a general purpose, followed by sub-objectives, criteria, and possible alternatives at the lowest criteria level. In this stage, KPI is given score. The score of a choice is obtained using the following formula.

$$
b o p_{i}=\sum_{i=1}^{n} b o_{i j} \times b c_{j},
$$

where $b o p_{i}$ is the score for $\mathrm{i}^{\text {th }}$ choice, $b c_{j}$ is the score related with the $j^{\text {th }}$ criterion and $b o_{i j}$ is the score of the $i$ choice for the $j$ criterion.

\subsection{Objective Matrix (OMAX)}

The OMAX scoring method consists of three steps, namely defining, quantifying, and monitoring. In the defining step the factors that influence performance are determined. In the quantifying step the performance achievement level is determined from the highest level (10) to the lowest (0). In the monitoring step, a recording of the results of the performance achievement is carried out.

\subsection{Traffic Light System}

The final stage in data analysis is grouping a performance indicator based on the level of achievement. If the target in a performance indicator has been reached and does not require improvement, it will be grouped in green. Vice versa, if the target has not been achieved, it will be grouped into yellow or red depending on the level of achievement. This grouping is useful to make it easier to identify performance indicators that have not met the target while determining recommendations for appropriate improvements.

\section{Results}

The key stakeholders of the Depeha village's LPD consist of the following: (1) Customers: LPD customers consisting of savings customers and credit customers. (2) Employees: consists of seven people, namely the head of the LPD who is also a secretary / administration, a treasurer, a credit collector, three savings collectors, and a cleaning service. (3) Village Rulers and Local Communities: the Government of Depeha village and local residents who live around the LPD in Depeha village. The following is an identification of five performance prism perspectives (Fig. 2).

\subsection{Scoring Design Results Performance Measurement}

The target for each KPI is scale five, while the lower limit of achieving KPI is scale zero. The measurement results can be seen in Table 1. After each KPI is given a scale, the next stage is to give a score using the OMAX (Objective Matrix) method and compare between the measurement scale and the performance scale. 


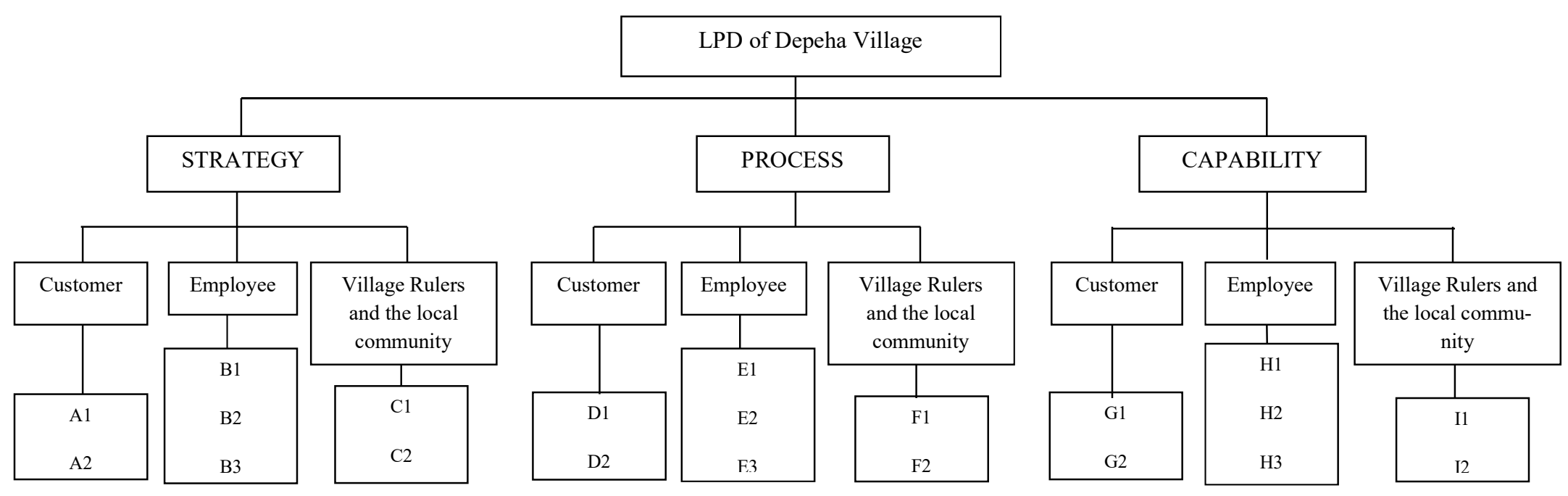

Note:

\begin{tabular}{|c|c|c|}
\hline STRATEGY & PROCESS & CAPABILITY \\
\hline Excellent service (A1) & Detailed information provided (D1) & Creative Marketing (G1) \\
\hline The implementation of door to door system (A2) & $\begin{array}{l}\text { The numbers of complaints and time to handle the } \\
\text { complaints (D2) }\end{array}$ & The ratio of complaints being solved (G2) \\
\hline $\begin{array}{l}\text { The numbers of plans for the procurement of the } \\
\text { equipment (B1) }\end{array}$ & Number of actualized equipment (E1) & $\begin{array}{l}\text { The ratio of work equipment procurement plan with } \\
\text { the number of equipment being actualized (H1) }\end{array}$ \\
\hline The number of planned training (B2) & The number of actualized training (E2) & Ratio of training planning being actualized (H2) \\
\hline $\begin{array}{l}\text { The level of effort to improve working shape } \\
\text { (B3) }\end{array}$ & The openness of communication patterns (E3) & Ratio of training planning being actualized (H3) \\
\hline $\begin{array}{l}\text { The numbers of credit applications }(\mathrm{C} 1) \\
\text { Maintain a positive image in the community }(\mathrm{C} 2)\end{array}$ & $\begin{array}{l}\text { The ratio of credit applications (F1) } \\
\text { Number of social activities being held (F2) }\end{array}$ & $\begin{array}{l}\text { The amount of credit fund budget (I1) } \\
\text { The amount of budget to organize social activities } \\
\text { (I2) }\end{array}$ \\
\hline
\end{tabular}

Fig. 2. Key Performance Indicator (KPI) Hierarchy Structure of LPD in Depeha Village 
Table 1

Achievement Measurement Results Of Each KPI (Score Table of Each Strategy Criteria Elements)

\begin{tabular}{|c|c|c|c|c|c|c|c|c|c|c|}
\hline \multirow{2}{*}{ No. } & \multirow{2}{*}{ Strategy } & \multicolumn{6}{|c|}{ Scores Given by the Respondents Number } & \multirow{2}{*}{ Total } & \multirow{2}{*}{$\begin{array}{c}\text { Actual } \\
\text { Score }\end{array}$} & \multirow[t]{2}{*}{ Category } \\
\hline & & 1 & 2 & 3 & 4 & 5 & 6 & & & \\
\hline 1 & Excellent service towards the customer(A1) & 4 & 4 & 3 & 3 & 4 & 5 & 23 & 3.83 & Good Enough \\
\hline 2 & Door to door system (A2) & 4 & 5 & 4 & 4 & 4 & 4 & 25 & 4.17 & Good \\
\hline 4 & The numbers of plans for the procurement of the equipment (B2) & 4 & 3 & 3 & 4 & 4 & 5 & 23 & 3.83 & Good Enough \\
\hline 5 & The number of planned training to improve the employee's skill (B3) & 4 & 4 & 2 & 3 & 5 & 4 & 22 & 3.67 & Good Enough \\
\hline 6 & The numbers of credit applications $(\mathrm{C} 1)$ & 3 & 5 & 5 & 3 & 4 & 5 & 25 & 4.17 & Good \\
\hline 7 & Process & & & & & & & & & \\
\hline 8 & Providing detailed information on LPD’s service (D1) & 5 & 4 & 4 & 4 & 4 & 5 & 26 & 4.33 & Good \\
\hline 9 & The numbers of customers' complaints and service time (D2) & 3 & 3 & 3 & 3 & 4 & 4 & 20 & 3.33 & Good Enough \\
\hline 10 & The numbers of available equipment (E1) & 5 & 5 & 5 & 4 & 4 & 4 & 27 & 4.5 & Good \\
\hline 11 & The realization of training plans (E2) & 5 & 4 & 3 & 3 & 4 & 4 & 23 & 3.83 & Good Enough \\
\hline 12 & Communication between employees (E3) & 5 & 5 & 5 & 5 & 4 & 5 & 29 & 4.83 & Good \\
\hline 13 & The ratio of credit applications (F1) & 4 & 3 & 4 & 3 & 3 & 5 & 22 & 3.67 & Good Enough \\
\hline 14 & The numbers of social activities being held (F2) & 5 & 3 & 4 & 3 & 4 & 5 & 24 & 4 & Good \\
\hline 15 & Creative marketing (G1) & 4 & 4 & 3 & 3 & 2 & 4 & 20 & 3.33 & Good Enough \\
\hline 16 & The ratio of customers' complaints being solved (G2) & 3 & 3 & 3 & 4 & 3 & 4 & 20 & 3.33 & Good Enough \\
\hline 17 & $\begin{array}{l}\text { The ratio of work equipment procurement plan with the number of equipment } \\
\text { being actualized (H1) }\end{array}$ & 4 & 5 & 4 & 3 & 4 & 3 & 23 & 3.83 & Good Enough \\
\hline 18 & $\begin{array}{l}\text { The ratio of employees' training plan with the employees' training being ac- } \\
\text { tualized (H2) }\end{array}$ & 3 & 4 & 3 & 3 & 4 & 4 & 21 & 3.5 & Good Enough \\
\hline 19 & The number of employees' complaints being accepted and solved (H3) & 3 & 4 & 4 & 3 & 1 & 4 & 19 & 3.17 & Good Enough \\
\hline 20 & The amount of credit fund budget (I1) & 4 & 4 & 4 & 4 & 4 & 4 & 24 & 4 & Good \\
\hline 21 & The amount of budget to organize social activities (I2) & 4 & 5 & 4 & 4 & 3 & 5 & 25 & 4.16 & Good \\
\hline
\end{tabular}

Source: Independent Observation 
The scoring of each KPI by using the OMAX (Objective Matrix) method on the Strategy criteria is presented in Table 2. The scoring results of each KPI using the OMAX method (Objective Matrix) on the Process criteria are presented in the Table 3. The scoring of each KPI using the OMAX method (Objective Matrix) on the Capability criteria is presented in the Table 4. Table 5 that presents a recapitulation of KPI performance of Stakeholder Satisfaction and KPI of Stakeholder Contributions.

Table 2

OMAX Table of Strategy KPI

\begin{tabular}{|c|c|c|c|c|c|c|c|}
\hline \multirow{3}{*}{ KPI } & \multicolumn{7}{|c|}{ KPI } \\
\hline & \multicolumn{2}{|c|}{ Customer } & \multicolumn{3}{|c|}{ Employee } & \multicolumn{2}{|c|}{ Village Rulers and Local } \\
\hline & $\mathrm{A} 1$ & A2 & B1 & B2 & B3 & $\mathrm{C} 1$ & $\mathrm{C} 2$ \\
\hline Achievement & 3.83 & 4.17 & 3.5 & 3.83 & 3.67 & 4.17 & 4.5 \\
\hline 10 & 5.00 & 5.00 & 5.00 & 5.00 & 5.00 & 5.00 & 5.00 \\
\hline 9 & 4.50 & 4.50 & 4.50 & 4.50 & 4.50 & 4.50 & 4.50 \\
\hline 8 & 4.00 & 4.00 & 4.00 & 4.00 & 4.00 & 4.00 & 4.00 \\
\hline 7 & 3.50 & 3.50 & 3.50 & 3.50 & 3.50 & 3.50 & 3.50 \\
\hline 6 & 3.00 & 3.00 & 3.00 & 3.00 & 3.00 & 3.00 & 3.00 \\
\hline 5 & 2.50 & 2.50 & 2.50 & 2.50 & 2.50 & 2.50 & 2.50 \\
\hline 4 & 2.00 & 2.00 & 2.00 & 2.00 & 2.00 & 2.00 & 2.00 \\
\hline 3 & 1.50 & 1.50 & 1.50 & 1.50 & 1.50 & 1.50 & 1.50 \\
\hline 2 & 1.00 & 1.00 & 1.00 & 1.00 & 1.00 & 1.00 & 1.00 \\
\hline 1 & 0.50 & 0.50 & 0.50 & 0.50 & 0.50 & 0.50 & 0.50 \\
\hline 0 & 0.00 & 0.00 & 0.00 & 0.00 & 0.00 & 0.00 & 0.00 \\
\hline Actual Score & 8 & 8 & 7 & 8 & 7 & 8 & 9 \\
\hline KPI Score & 0.2 & 0.8 & 0.383 & 0.233 & 0.383 & 0.35 & 0.65 \\
\hline Performance Score & 1.6 & 6.4 & 2.681 & 1.864 & 2.681 & 2.8 & 5.85 \\
\hline Stakeholder Score & \multicolumn{2}{|c|}{0.483} & \multicolumn{3}{|c|}{0.033} & \multicolumn{2}{|c|}{0.483} \\
\hline
\end{tabular}

Source: Independent Observation

Table 3

OMAX Table of Process KPI

\begin{tabular}{|c|c|c|c|c|c|c|c|}
\hline \multirow{3}{*}{ KPI } & \multicolumn{7}{|c|}{ KPI } \\
\hline & \multicolumn{2}{|c|}{ Customer } & \multicolumn{3}{|c|}{ Employee } & \multicolumn{2}{|c|}{ Village Rulers and Local } \\
\hline & D1 & D2 & E1 & E2 & E3 & F1 & F2 \\
\hline Achievement & 4.33 & 3.33 & 4.5 & 3.83 & 4.83 & 3.67 & 4 \\
\hline 10 & 5.00 & 5.00 & 5.00 & 5.00 & 5.00 & 5.00 & 5.00 \\
\hline 9 & 4.50 & 4.50 & 4.50 & 4.50 & 4.50 & 4.50 & 4.50 \\
\hline 8 & 4.00 & 4.00 & 4.00 & 4.00 & 4.00 & 4.00 & 4.00 \\
\hline 7 & 3.50 & 3.50 & 3.50 & 3.50 & 3.50 & 3.50 & 3.50 \\
\hline 6 & 3.00 & 3.00 & 3.00 & 3.00 & 3.00 & 3.00 & 3.00 \\
\hline 5 & 2.50 & 2.50 & 2.50 & 2.50 & 2.50 & 2.50 & 2.50 \\
\hline 4 & 2.00 & 2.00 & 2.00 & 2.00 & 2.00 & 2.00 & 2.00 \\
\hline 3 & 1.50 & 1.50 & 1.50 & 1.50 & 1.50 & 1.50 & 1.50 \\
\hline 2 & 1.00 & 1.00 & 1.00 & 1.00 & 1.00 & 1.00 & 1.00 \\
\hline 1 & 0.50 & 0.50 & 0.50 & 0.50 & 0.50 & 0.50 & 0.50 \\
\hline $\mathbf{0}$ & 0.00 & 0.00 & 0.00 & 0.00 & 0.00 & 0.00 & 0.00 \\
\hline Actual Score & 9 & 7 & 9 & 8 & 10 & 7 & 8 \\
\hline KPI Score & 0.5 & 0.5 & 0.333 & 0.483 & 0.183 & 0.5 & 0.5 \\
\hline Performance Score & 4.5 & 3.5 & 2.997 & 3.864 & 1.83 & 3.5 & 4 \\
\hline Stakeholder Score & \multicolumn{2}{|c|}{0.483} & \multicolumn{3}{|c|}{0.033} & \multicolumn{2}{|c|}{0.483} \\
\hline
\end{tabular}

Source: Independent Observation

\subsection{Color Classification of the Results of Performance Measurement Design}

After the classification is performed by using the Traffic Light System, it is known that there are thirteen KPIs in the green category and eight KPIs in the yellow category. In the Strategy criteria there are five KPIs in the green category, namely A1 KPI, A2 KPI, KPI B2, KPI C1, and KPI C2. In addition to the green category, there are also two yellow category KPIs, namely KPI B1 and KPI B3. In the Process criteria there are five KPIs in the green category, namely KPI D1, KPI E1, KPI E2, KPI E3, and KPI F2. Other KPIs are in the yellow category, namely D2 KPI and F1 KPI. On the Capability criteria there are 
three green categories of KPIs, namely H1 KPI, I1 KPI and KPI 12. Besides, there are four KPIs in the yellow category, namely G1 KPI, G2 KPI, H2 KPI, and H3 KPI.

Table 4

OMAX Table of Capability KPI

\begin{tabular}{|c|c|c|c|c|c|c|c|}
\hline \multirow{2}{*}{ KPI } & \multicolumn{2}{|c|}{ Customer } & \multicolumn{3}{|c|}{ Employee } & \multicolumn{2}{|c|}{ Village Rulers and Local Community } \\
\hline & G1 & $\mathrm{G} 2$ & $\mathrm{H} 1$ & $\mathrm{H} 2$ & $\mathrm{H} 3$ & I1 & $\mathrm{I} 2$ \\
\hline Achievement & 3.33 & 3.33 & 3.83 & 3.5 & 3.17 & 4 & 4.16 \\
\hline 10 & 5.00 & 5.00 & 5.00 & 5.00 & 5.00 & 5.00 & 5.00 \\
\hline 9 & 4.50 & 4.50 & 4.50 & 4.50 & 4.50 & 4.50 & 4.50 \\
\hline 8 & 4.00 & 4.00 & 4.00 & 4.00 & 4.00 & 4.00 & 4.00 \\
\hline 7 & 3.50 & 3.50 & 3.50 & 3.50 & 3.50 & 3.50 & 3.50 \\
\hline 6 & 3.00 & 3.00 & 3.00 & 3.00 & 3.00 & 3.00 & 3.00 \\
\hline 5 & 2.50 & 2.50 & 2.50 & 2.50 & 2.50 & 2.50 & 2.50 \\
\hline 4 & 2.00 & 2.00 & 2.00 & 2.00 & 2.00 & 2.00 & 2.00 \\
\hline 3 & 1.50 & 1.50 & 1.50 & 1.50 & 1.50 & 1.50 & 1.50 \\
\hline 2 & 1.00 & 1.00 & 1.00 & 1.00 & 1.00 & 1.00 & 1.00 \\
\hline 1 & 0.50 & 0.50 & 0.50 & 0.50 & 0.50 & 0.50 & 0.50 \\
\hline o & 0.00 & 0.00 & 0.00 & 0.00 & 0.00 & 0.00 & 0.00 \\
\hline Actual Score & 7 & 7 & 8 & 7 & 6 & 8 & 8 \\
\hline KPI Score & 0.35 & 0.65 & 0.233 & 0.383 & 0.383 & 0.5 & 0.5 \\
\hline Performance Score & 2.45 & 4.55 & 1.864 & 2.681 & 2.298 & 4 & 4 \\
\hline Stakeholder Score & \multicolumn{2}{|c|}{0.483} & \multicolumn{3}{|c|}{0.033} & \multicolumn{2}{|c|}{0.483} \\
\hline
\end{tabular}

Table 5

Recapitulation of KPI Performance of Stakeholder Satisfaction and Contributions

\begin{tabular}{cccc}
\hline Stakeholder Satisfaction KPI & Performance Score & Stakeholder Contributions KPI & Performance Score \\
\hline A1 & 1.600 & A2 & 6.400 \\
B1 & 2.681 & B3 & 2.681 \\
B2 & 1.864 & C2 & 5.850 \\
C1 & 2.800 & D2 & 3.500 \\
D1 & 4.500 & E3 & 1.830 \\
E1 & 2.997 & F2 & 4.000 \\
E2 & 3.864 & G2 & 4.550 \\
F1 & 3.500 & H3 & 2.298 \\
G1 & 2.450 & I2 & 4.000 \\
H1 & 1.864 & - & - \\
H2 & 2.681 & - & - \\
\hline T1 & 4.000 & Total & 35.289 \\
\hline Average & 35.161 & Average & 3.921 \\
\hline Source: Independent Observation & 2.930 & &
\end{tabular}

Source: Independent Observation

\section{Discussion}

According to the results, it can be seen that the performance value of each element of the performance indicator has shown the actual performance of the LPD of Depeha village. The performance of the KPI A2 was far greater than the KPI A1 and so on so that it is known that KPI A2, which is the application of a door to door system, has the highest performance core of all KPIs. On the other hand, the lowest KPI achievement was achieved by the A1 KPI or the implementation of excellent service to customers. Table 3 shows the total performance score for each criterion where Strategy KPI criteria receives a performance score of 8.280 with a mark score of 0.483 which is the greatest score among the three KPI criteria. The Process receives the performance value of 7.774 with a score of 0.333 , while the Capability receives a performance value of 7.471 with a score of 0.183 . This means that each KPI criterion has shown optimal achievement. It has also shown that the total performance score for the LPD in Depeha village was 7.955. This core has exceeded the performance core targeted by the LPD of Depeha village, which was 7.00. We may also observe that the performance score of Stakeholder Satisfaction was assessed from the average compiler of KPI which is 2.930. The performance score of Stakeholder Contributions is assessed from the average compiler of KPI to be 3,921. Thus, it can be interpreted that the contributions given by stakeholders are higher than the satisfaction they get from the LPD. Based on the analysis using the 
Traffic Light System, it can be seen that the performance of Depeha village's LPD is in the yellow category with a performance score of 7.955. Even though this score has exceeded the expected performance score, which was 7.00, the LPD still has to be careful with various possibilities. The results of the analysis also show that there were $8 \mathrm{KPIs}$ out of $21 \mathrm{KPIs}$ that fall into the yellow category. The yellow category means that the KPI entered the category of having good achievement, but has not yet achieved the expected performance. Out of eight KPIs that fall into the yellow category, four of them are elements of the KPI Capability. This means that the capabilities of the Depeha village's LPD are still inadequate compared with the established strategies and processes implemented. The KPIs included in the yellow category include the number of equipment procurement plans (B1) and the number of training plans to improve the employee skills (B3) on the Strategy criteria, the number of customer complaints and service time (D2) and the credit application ratio with the accepted credit ( F1) on Process criteria, creative marketing (G1), ratio of customer complaints being solved (G2), training planning ratio to employees with training actualization (H2), and number of employee complaints received and solved (H3) on Capability Criteria. Based on Table 5, it can be seen that the satisfaction received by stakeholders was not equivalent to the contribution given. The lowest stakeholder satisfaction was owned by KPI A1 or excellent service to customers, KPI B2 or the number of planned trainings, and KPI H1 or planning ratio of procurement of equipment with the actualization, each of which has a performance score below 2.00. Based on the results of the analysis, the LPD should pay more attention to the importance of each KPI because the KPI that gets a high score actually gets the lowest performance score due to low mark score such as the A1 KPI. Similarly, the B2 KPI which has the highest score in the Employee Strategy criterion actually gets the lowest performance score. This also applies to the H1 KPI. Giving the order of importance is necessary because it will give priority to the things that the LPD must develop. Based on Table 6, it can be seen that excellent service has the lowest performance score of all KPIs because this KPI has a low mark score which means that this KPI is less important than other elements in the same criterion. This will have an effect on the customers' reluctance to come to the LPD because the excellent service provided to customers who come is considered less important by the LPD. This customer reluctance will have an impact on the amount of savings and credit. However, since collectors routinely come to the customer's house (door to door system), savings and some credit can still be collected. This applies if the customer is always at his/her house. If the customer is rarely at home and is reluctant to come to the LPD office, it is likely that the customer will rarely save or pay off the credit. If customers rarely fulfill their obligations to pay off credit, then bad debt will be even higher. Therefore, the LPD should reconsider the order of importance of each performance indicator. In summary, there were four KPI Capabilities that fall into the Yellow category, which is quite high compared with the criteria of the strategy and process, each of which has two KPIs in the yellow category. This means that the capability of the LPD to carry out a good process is still inadequate. Therefore, the LPD should pay attention to the capabilities needed to carry out the strategy so that the process can run better.

\section{Conclusion}

Based on the results, it can be concluded that it not only the strategy, process, and capability could influence on the LPD of Depeha village, but stakeholders' satisfaction and stakeholders' contributions also had some effects on the LPD. This can be seen from the strategy formulation carried out by the LPD based on the determinants of satisfaction of the stakeholders. The design results show that LPD stakeholders in Depeha village includes customers, employees, and village rulers and local community. The performance measurement system contains 21 KPIs, which consist of 6 Customer KPIs, 9 Employee KPIs, and 6 village rulers and local community KPI which are classified into three criteria, namely strategy, process, and capability. From those three criteria, the Strategy criteria maintained the highest performance score according to the highest mark score. Based on the Traffic Light System, it is known that there were eight KPIs in the Yellow category, which means that the achievement of the KPI was good enough but has not met the expected target yet. The KPIs fall into yellow category are: an improvement in working conditions (KPI B1), the number of training plans to improve employee skills (KPI B3), number of customer complaints and service time (KPI D2), credit application ratio being accepted (F1 KPI), creative marketing (KPI G1), ratio of customers' complaints being solved (GPI KPI), training 
planning ratio to employees with training actualization (H2 KPI), and number of employee complaints received and solved (H3 KPI). KPIs with performance scores below 2.00 actually do not enter the Yellow category. This shows that sorting the level of importance compared to the implementation of each indicator is still less relevant.

\section{References}

Adianto, Saryatmo, M. A., \& Gunawan, A. S. (2014). Analisis Pengukuran Kinerja Perusahaan Dengan Metode Performance Prism dan Scoring Objective Matrix (OMAX) Pada PT. BPAS. Sinergi, 18(2), 61-70.

Bourgeois, R. (2005). Analytical Hierarchy Process: an Overview. Bogor: UNCAPSA-UNESCAP.

Cahyawati, A. N., Pratikto, \& Soenoko, R. (2013). Analisis Pengukuran Kinerja Rumah Sakit Dengan Menggunakan Metode Performance Prism. Jemis, 1(1), 1-7.

Kennerley, M., \& Neely, A. (2002). A Framework of the Factors Affecting the Evolution of Performance Measurement Systems. International Journal of Operations \& Production Management, 22(11), 1222-1245.

Kumar, V. V. P., \& Gupta, V. K. (2011). Analysis of Performance Indicators on Sustenance of Micro Finance Institutes: A Comparative Study of East Asian \& Pacific, and South Asian Countries. Research Journal of Finance and Accounting, 2(3), 1-15.

Mersland, R., \& Strøm, R. Ø. (2009). Performance And Governance In Microfinance Institutions. Journal of Banking and Finance, 33(4), 662-669.

Mustafa, A. K. A., \& Saat, M. M. (2013). Microfinance Institutions Performance Measurement: Introducing a New Performance Measurement Framework. Middle-East Journal of Scientific Research, 15(11), 1618-1628.

Najmi, M., Etebari, M., \& Emami, S. (2012). A framework to review Performance Prism. International Journal of Operations \& Production Management, 32(10), 1124-1146.

Neely, A. (2005). The evolution of performance measurement research: Developments in the last decade and a research agenda for the next. International Journal of Operations \& Production Management, 25(12), 1264 1277.

Neely, A., Adams, C., \& Kennerley, M. (2002). The Performance Prism: The Scorecard for Measuring and Managing Business Success. United Kingdom: Financial Times Prentice Hall.

Riggs, J. L. (1987). Production System Planning, Analysis and Control. Singapore: John Wiley \& Sons Inc.

Rotich, I., Lagat, C., \& Kogei, J. (2015). Effects of microfinance services on the performance of small and medium enterprises in Kenya. African Journal of Business Management, 9(5), 206-211.

Saaty, T. L. (2008). Decision Making With The Analytic Hierarchy Process. International Journal Services Sciences, 1(1), 83-98.

Sawang, S. (2011). Key performance indicators for innovation implementation : perception vs. actual usage. Asia Pacific Management Review, 16(1), 23-29.

Sharma, M. K., Bhagwat, R., \& Dangayach, G. S. (2005). Practice of performance measurement: experience from Indian SMEs. International Journal of Globalisation and Small Business, 1(2), 183-213.

Subhan, M., \& Ghani, A. B. A. (2011). The Formulating Growth Strategy of Aceh Port System in Indonesia: An AHP Approach. Gadjah Mada International Journal of Business, 13(1), 45-64.

Taticchi, P., Tonelli, F., \& Cagnazzo, L. (2010). Performance measurement and management: a literature review and a research agenda. Measuring Business Excellence, 14(1), 4-18.

Ukil, M. I., \& Akkas, M. A. (2017). Determining Success Factors For Effective Strategic Change: Role Of Middle Managers' Strategic Involvement. Serbian Journal of Management, 12(1), 29-40.

Velimirović, D., Velimirović, M., \& Stanković, R. (2011). Role And Importance Of Key Performance Indicators Measurement. Serbian Journal of Management, 6(1), 63-72.

Youngbantao, U., \& Rompho, N. (2015). The Uses of Measures in Performance Prism in Different Organizational Cultures. Journal of Accounting and Finance, 15(6), 122-128.

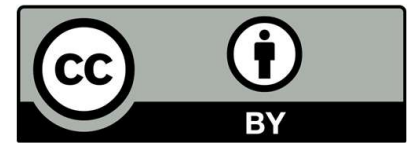

(C) 2020 by the authors; licensee Growing Science, Canada. This is an open access article distributed under the terms and conditions of the Creative Commons Attribution (CCBY) license (http://creativecommons.org/licenses/by/4.0/). 